\title{
Efficacy of Sterilization Methods and Their Influence on the Electrochemical Behavior of Plain Carbon Steel
}

\author{
Carla Giai, ${ }^{a}$ Mauricio Rincón-Ortiz, ${ }^{\text {b }}$ Mariano A. Kappes, ${ }^{c}$ John Senko, \\ and Mariano Iannuzzi ${ }^{\mathrm{e}, \mathrm{z}}$
}

\author{
${ }^{a}$ Department of Chemical and Biomolecular Engineering, University of Akron, Akron, Ohio 44325, USA \\ ${ }^{b}$ Universidad Industrial de Santander, Santander, Colombia \\ ${ }^{c}$ Instituto Sabato, Comisión Nacional de Energía Atómica, San Martín, Argentina \\ ${ }^{d}$ Department of Geosciences and Department of Biology, University of Akron, Akron, Ohio 44325, USA \\ ${ }^{e}$ Norwegian University of Science and Technology, Trondheim, Norway
}

\begin{abstract}
Minimizing contamination of control treatments in microbiologically influenced corrosion (MIC) studies is of critical importance. Metal sterilization procedures should not alter the surface nor affect the inherent susceptibility of the metal to corrosion while adequately deactivating biological activity. However, there is no consensus in the literature regarding such procedures due to, in part, the lack of a universally accepted methodology. This investigation evaluates various sterilization methods for carbon steel concerning practicality, efficacy, and effects on the electrochemical response of the metal. Three sterilization procedures using i) dry heat, ii) ethanol, or iii) glutaraldehyde as sterilizing agents were evaluated. Even though all sterilization approaches were equally effective in eliminating microorganisms and spores from the metal surface, dry heating at $170^{\circ} \mathrm{C}$ in an inert atmosphere was identified as the most convenient sterilization method regarding practicality and consistency in the electrochemical response of the metal. Sterilization of carbon steels in $75 \mathrm{vol} \%$ ethanol and glutaraldehyde, as well as alcohol followed by flaming, is discouraged given the large dispersion in corrosion response caused by the exposure to the sterilization media.

(C) The Author(s) 2016. Published by ECS. This is an open access article distributed under the terms of the Creative Commons Attribution 4.0 License (CC BY, http://creativecommons.org/licenses/by/4.0/), which permits unrestricted reuse of the work in any medium, provided the original work is properly cited. [DOI: 10.1149/2.0271610jes] All rights reserved.
\end{abstract}

Manuscript submitted June 7, 2016; revised manuscript received July 26, 2016. Published August 8, 2016.

Microbiologically influenced corrosion (MIC) studies deal with the role microorganisms have on electrochemical processes leading to corrosion. ${ }^{1-3}$ As bacteria and fungi interact with the metal surface and its environment, they are able "to initiate, facilitate or accelerate the corrosion reaction without changing its electrochemical nature." 4 The ubiquitous nature of some microorganisms can present a challenge to MIC studies, where contamination with species of diverse metabolic capabilities can alter the result of the experiments. Therefore, minimizing contamination from foreign microorganisms to maintain a microbial community that properly reflects the desired microbial composition (i.e. these being an environmental sample or a specifically defined community) is of critical importance in MIC research.

Most of the components used in an MIC study (i.e. glassware, reactors or electrochemical cells, and solutions) can be sterilized following standard sterilization procedures ${ }^{5}$ used by microbiologists; however, there is no consensus regarding sterilization procedures for metal samples in the literature. In the ideal situation, the sterilization methodology should kill all microorganisms and spores on the metal, but it should not alter its surface nor affect the inherent susceptibility of the metal on corrosion.

In a literature survey of over 200 papers dealing with MIC of carbon and low alloy steels, there were over 20 different procedures to sterilize metal samples, Table I. Some of the methods described in the literature range from autoclaving steel stubs inside of watertight containers, submerging the stubs in $70 \mathrm{vol} \%$ ethyl alcohol and flaming them before inoculation, ${ }^{6}$ to immersion in a $2000 \mathrm{ppm}$ chlorine solution (i.e. approximately 4000 times the residual chlorine level required to treat natural seawater $)^{7-9}$ for 30 minutes, followed by overnight treatment with glutaraldehyde. ${ }^{10}$ Others employed fine $\mathrm{Mg}(\mathrm{OH})_{2}$ suspensions and high-purity acetone; ${ }^{11}$ overnight immersion in 70 vol\% ethanol, followed by drying aseptically in air; $;^{12} 9 \mathrm{~h}$ heat treatments at $130^{\circ} \mathrm{C}$ in glass beakers covered with aluminum foil ${ }^{13}$ or the use of ultraviolet light. ${ }^{14}$

It is important to mention that the methods listed in Table I correspond roughly to the same number of papers explicitly describing the sterilization procedures in the methodology section of the manuscript. Indeed, most of the papers reviewed do not describe sterilization procedures in enough detail to be reproduced by other laboratories. It

${ }^{\mathrm{z}}$ E-mail: mariano.iannuzzi@ntnu.no is likely that increasing the number of surveyed papers will increase those figures. Moreover, there has been no systematic study on the effects of the sterilization method on the metal surface and the corresponding corrosion response to date.

The primary objective of this work was to determine the most convenient sterilization method for plain carbon steel in terms of practicality in typical laboratory settings, efficacy, and effects that such procedures may have on the electrochemical response of the metal. Given that the electrochemical and corrosion responses in a given environment depend on the surface condition of the sample, the electrochemical response was studied using the same environment before and after sterilization. Therefore, differences could be directly correlated with changes in surface condition caused by the sterilization treatment.

\section{Materials and Methods}

Metal sample preparation.-Electrochemical tests were performed on cylindrical UNS G10180 (AISI 1018) plain low carbon steel specimens in the cold-rolled and annealed condition with an approximate area of $5 \mathrm{~cm}^{2}$. Before sterilization, samples were wet abraded to a 600-grit finish using SiC paper, ultrasonically cleaned in 200-proof ethyl alcohol, rinsed with acetone and deionized water, and finally dried using compressed argon. Specimens were stored temporarily in a desiccator and used within $24 \mathrm{~h}$.

Coupons used for determining the efficacy of the sterilization procedures were prepared following the same steps; however, flat UNS G10100 (AISI 1010) steel coupons with an approximate exposed area of $7 \mathrm{~cm}^{2}$ were used for this task. There are minimal differences in carbon content and microstructure between UNS G10100 and UNS G10180 (Table II), negligible for the purpose of this investigation. ${ }^{15,16}$

Sterilization methods.-The sterilization methods used in this study are summarized in Table III. These methods were selected because of (a) their broad use in microbiology laboratories and/or health-related institutions, (b) their practicality or convenience for implementing in a standard laboratory setting, which included feasibility in storing sterilized coupons for relatively long times (i.e. more than 24 hours) instead of immediate use, (c) their a priori efficacy, and (d) their potential deleterious effects -or lack thereof- on metals. For instance, steam sterilization (i.e. in an autoclave) was not 
Table I. Summary of sterilization methodologies in MIC studies involving plain carbon steels. Methods are described as they appear in the literature. Over 200 papers dealing with MIC in carbon steels were surveyed. This list only includes papers describing sterilization procedures in enough detail to be reproduced by other laboratories.

Authors (year)

Beech and Gaylarde $(1991)^{6}$

Castañeda and Benetton $(2008)^{21}$

de França and others $(1996)^{68}$

Dorsey and others $(2005)^{10}$

Eckert and others $(2006)^{69}$ Edyvean and others
$(1992)^{70}$

González-Rodríguez and others $(2008)^{22}$ $\mathrm{Gu}$ and others $(1998)^{23}$

Li and others $(2001)^{24}$

Lugauskas and others $(2009)^{11}$

Miyanaga and others $(2007)^{14}$

Peng and Park (1994) ${ }^{71}$

Rodin and others $(2000)^{72}$ Royer and Unz (2002) ${ }^{73}$

Stadler and others $(2008)^{13}$

Stranger-Johannessen $(1987)^{74}$

Tanji and others (2002) ${ }^{75}$

Valencia-Cantero and others $(2003)^{76}$

Wen and others (2006) $)^{77}$

Yuan and Pehkonen $(2007)^{12}$
Alloy

BS970 (MS-II), SAE1020 (MS-I), BS316 (SS-II), AISI304L (SS-I)

SAE-1018 carbon steel (UNS G10180) coupon.

AISI 304 stainless steel (UNS S30400).

Multielectrode array sensor probes and UNS G10180 monitoring coupons in flow loop

Coupons machined from API 5L X42 grade pipe steel

AISI 316 stainless steel (UNS S31600) as part of modified Robbins devices (MRD)

AISI 1018 (UNS G10180) mild steel coupons

AISI 316 (UNS S31600) stainless steel coupon as a part of EIS cells

SAE 1018 (UNS G10180)

Low carbon steel, composition (wt \%): 0.05-0.12 C, 0.003-0.10 Cu, and $<0.07 \mathrm{P}$

Carbon steel coupons composition (wt\%): $99.71 \mathrm{Fe}, 0.03 \mathrm{C}, 0.01 \mathrm{Si}, 0.19$ Mn, 0.013 P, 0.0017 N, $0.026 \mathrm{Al}$ Steel coupons composition (wt $\%$ ): 0.01 $\mathrm{Si}, 0.01 \mathrm{P}, 0.19 \mathrm{Mn}, 0.01 \mathrm{~S}$, and $99.78 \mathrm{Fe}$

\section{Mild steel}

Music spring quality steel wire $(0.216$ mm diameter, ASTM A228/A228M)

Pure iron (Armco), carbon steel ST37, stainless steel AISI 304 (UNS S30400)

Painted steel plates

Carbon steel coupons composition (wt $\%$ ) of $99.71 \mathrm{Fe}, 0.03 \mathrm{C}, 0.19 \mathrm{Mn}, 0.017 \mathrm{~S}$, $0.013 \mathrm{P}$, and $0.01 \mathrm{Si}$, mounted in epoxy resin

High-carbon steel (1 wt\% C) and plain carbon steel $(0.015-0.020 \mathrm{wt} \% \mathrm{C})$

C1018 (UNS G10180) cylindrical coupon used as working electrode in bioreactor

Stainless steel AISI 304 (UNS S30400)
Metal sterilization/preparation procedures (after polishing, if applicable)

Stubs were autoclaved in watertight containers; before exposure to bacterial cultures, steels were immersed in $70 \mathrm{vol} \%$ alcohol, flamed, placed inside sterile universal bottles and allowed to cool.

Coupons were sterilized in $70 \mathrm{vol} \%$ ethanol solution for $30 \mathrm{~min}$ and maintained under sterile laminar air flow before the immersion in the electrochemical cells until use.

Coupons placed in field conditions were not sterilized; however, to test the direct effect of seawater, metal coupons were placed inside flasks containing $100 \mathrm{~mL}$ of seawater and sterilized at $120^{\circ} \mathrm{C}$ for $20 \mathrm{~min}$.

Flow loop was "sterilized" by circulating 2000 ppm chlorine solution for 30 minutes, followed by treatment with non-oxidizing biocide (glutaraldehyde) overnight. A small amount of glutaraldehyde was also added to the water following sterilization to provide additional protection from contamination during the first days of testing.

Coupons were ultrasonically cleaned in absolute ethanol and finally rinsed in acetone. After cleaning, the coupons were packaged in individual polyethylene bags in a dry nitrogen environment to prevent contact with moisture. The coupons were not exposed to air until immediately before installing in the test system. MRD were sterilized by filling them with 2.5 vol\% hypochlorous acid (commercial bleach) and allowed to stand for 2 hours; then, they were rinsed with sterile deionized water.

Cleaned coupons were sterilized with ethanol before exposure to the experimental media

The internal and external surfaces of the EIS cells were sterilized with $70 \mathrm{vol} \%$ ethanol and dried at room temperature in a laminar flow sterile hood.

Coupons were degreased with alcohol and then rinsed with sterilized, deionized water. Electrodes were sterilized in $70 \mathrm{vol} \%$ alcohol for 2 hours and then stored in clean bench until use.

Coupons were treated with a fine suspension of $\mathrm{Mg}(\mathrm{OH})_{2}$ and high purity acetone to minimize initial contamination of the surface with nutritive substances from the environment.

The coupon surface was disinfected by transilluminator for $5 \mathrm{~min}$.

Coupons were degreased with $100 \mathrm{vol} \%$ ethanol, rinsed with acetone and distilled water, dried with $\mathrm{N}_{2}$ blower, and stored in a desiccator before use; to inactivate microorganisms, glutaraldehyde was added to the non-inoculated solution. Clean coupons were placed in test tubes that were sterilized at $170^{\circ} \mathrm{C}$ for 3 hours. Wires were immersed in baths of acetone and $1.5 \mathrm{~N} \mathrm{HCl}$ for $15 \mathrm{~min}$. Cleaned wires were threaded through butyl rubber stoppers and the protruding regions on both sides were coated with an anticorrosive lacquer. The stopper/wire system was then fitted to serum bottles with sterile medium and purged with $\mathrm{N}_{2}$.

Coupons in Teflon holders were placed in a glass beaker, covered with aluminum foil and sterilized by heat-treatment for 9 hours at $130^{\circ} \mathrm{C}$. Further work requiring sterile conditions was performed in a clean bench.

Plates were sterilized by dipping in $0.1 \mathrm{vol} \%$ hydrogen peroxide prior to inoculation

Before being attached to the epoxy resin, polished coupons were cleaned ultrasonically in acetone for 15 minutes, air dried, and stored in a desiccator.

High-carbon steel coupons were cleaned by soaking in acetone for $30 \mathrm{~min}$ and then they were brushed with a toothbrush, using a modification of the method of Haruta et al. (1991). The carbon steel coupons were cleaned using a slight modification of the method of Bryant et al. (1991), subjected to ultrasonication in citric acid ( $5 \mathrm{wt} / \mathrm{vol} \%$ ) for $5 \mathrm{~min}$, and then rinsed in distilled water for $1 \mathrm{~min}$. The coupons were flamed and weighed, then placed in closed culture tubes containing salt-rich culture medium V9.

The bioreactor was autoclaved before each run.

Coupons were rinsed with deionized water thrice, followed by degreasing with acetone, then sterilized by immersion in $70 \mathrm{vol} \%$ ethanol for 8 hours and dried aseptically in air. Newly prepared samples were immediately exposed to the test medium. 
Table II. Alloy nominal composition (wt\%).

\begin{tabular}{cccccc}
$\begin{array}{c}\text { UNS } \\
\text { designation }\end{array}$ & $\begin{array}{c}\text { AISI } \\
\text { designation }\end{array}$ & $\mathrm{C}$ & $\mathrm{Mn}$ & $\begin{array}{c}\mathrm{P} \\
(\max )\end{array}$ & $\begin{array}{c}\mathrm{S} \\
(\max )\end{array}$ \\
\hline G10100 & 1010 & $0.08-0.13$ & $0.30-0.60$ & 0.040 & 0.050 \\
G10180 & 1018 & $0.15-0.20$ & $0.60-0.90$ & 0.040 & 0.050
\end{tabular}

selected because of known damaging effects of moist heat on carbon steel, ${ }^{17}$ and because isolating the coupon on a sealed container before autoclaving could reduce the efficacy of the method by limiting steam-microorganism contact, which is necessary for optimal sterilization by autoclaving. ${ }^{18}$ Similarly, the use of oxidizing agents such as chlorine compounds (e.g. sodium hypochlorite solutions) or hydrogen peroxide solutions was avoided for similar reasons., ${ }^{7,9}$

As shown in Table III, one of the selected methods involved using dry heat (i.e. drying oven). Even though the main disadvantages of dry heat for sterilizing purposes are the slow heat penetration and microbial killing rates, it is a reliable sterilization method commonly used in healthcare facilities. ${ }^{19,20}$ The most commonly used time-temperature relationships are $170^{\circ} \mathrm{C}$ for 60 minutes, $160^{\circ} \mathrm{C}$ for 120 minutes, and $150^{\circ} \mathrm{C}$ for 150 minutes; warming up and cooling down times should be added to the total time. ${ }^{20}$ For this study, samples were treated at $170^{\circ} \mathrm{C}$ for 3 hours (i.e. including warming up and cooling down times) based on the temperature profile of the oven. Although the gas composition of the atmosphere at which the coupon is exposed does not influence the killing efficacy of the method, ${ }^{20}$ it might affect the surface properties of the specimen when heated, possibly affecting the corrosion response of the sample. Moreover, heat itself can promote the formation of surface oxides. Therefore, specimens for electrochemical testing were dry heated under two different atmospheric conditions: i) filtered air and ii) an inert argon atmosphere.

To perform dry heat sterilization, $100 \mathrm{~mL}$ heat resistant glass flasks containing the polished, clean coupons were flushed for about one hour. Flushing was performed through a hole in the flasks' heat resistant screw threaded cap, which had PTFE-silicone septa that were thermally stable up to $180^{\circ} \mathrm{C}$. The temperature profile of the oven was established before sterilization. The temperature profile was obtained using thermocouples placed inside the flasks, positioned at the center of the vial. During dry heat sterilization, samples were located within the plateau of the oven. After sterilization, flasks remained sealed until testing.

Another sterilization method consisted in using an ethyl alcohol solution in water as a chemical disinfectant. In healthcare facilities, ethyl alcohol solutions in water (60-90 vol\%) are rapidly bactericidal, tuberculocidal, fungicidal, and virucidal. ${ }^{19}$ Water solutions have been found more efficient in denaturing proteins than 200-proof ethyl alcohol, although they may lack sporicidal action and cannot penetrate protein-rich materials. ${ }^{19}$ Following methodologies described in the literature, e.g., ${ }^{6,21-24}$ and personal communications with other MIC investigators at the University of Akron, ${ }^{25}$ three exposure times were selected. The first two consisted in immersing abraded, clean coupons in 75 vol\% ethanol solution for 15 or 18 hours, trying to replicate what in the literature is referred to as "overnight" exposure. Shorter immersion times had resulted in contamination issues in past MIC experiments. ${ }^{25}$ The third method, i.e. dipping in a 75 vol $\%$ ethyl alcohol solution followed by flaming, is a conventional method for sterilizing metal equipment such as loops and tweezers in microbiol-

Table III. Sterilization methods.

Dry heat

75 vol\% ethyl alcohol
Sealed container, air Sealed container, argon

Rapid immersion followed by flaming Overnight immersion, 15 hours Overnight immersion, 18 hours Overnight immersion, 15 hours ogy laboratories. In both cases, after prolonged or rapid immersion, coupons had to be used immediately for electrochemical testing.

The third and final sterilization method consisted of using a glutaraldehyde solution. According to Rutala and others, ${ }^{19}$ activated aqueous glutaraldehyde solutions (i.e., alkaline solutions) have gained acceptance as a disinfectant and chemical sterilant in healthcare settings because of their microbicidal properties and non-corrosive action on equipment. Usually, 2 vol\% glutaraldehyde solutions buffered to $\mathrm{pH}$ 7.5-8.0 are effective in killing microorganisms; however, long exposure times are required. ${ }^{19}$ Additionally, special safety measures are recommended due to the known health hazards associated with glutaraldehyde exposure. ${ }^{19}$ Therefore, for this method, coupons were immersed in 2 vol\% glutaraldehyde (pentane-1,5-dial) aqueous solution, $\mathrm{pH}$ 8.0, for 15 hours. After immersion, coupons had to be used immediately for electrochemical testing. As with ethyl alcohol, exposure times were selected to replicate an "overnight" exposure. ${ }^{10}$

Efficacy of sterilization methods.-The effectiveness of all sterilization procedures was determined based on the ability to cultivate organisms after treatment of the coupons as follows. In the direct method, sterilized samples were incubated for 3-5 days under oxic conditions at room temperature in a sterile rich medium (LuriaBertani, hereafter LB, broth containing -per liter- $5.0 \mathrm{~g}$ of yeast extract

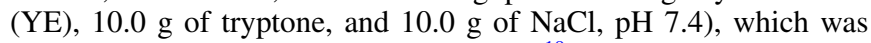
sterilized in single batches by autoclaving. ${ }^{19}$ Coupon transference to the sterilized medium was done under sterile conditions. Controls included flasks containing (i) sterilized medium and no coupons (control 1), and (ii) sterilized medium and non-sterilized coupons (control 2). Glassware as well as all other instrumentation was sterilized before use by autoclaving and by ethanol immersion followed by flaming immediately prior to use. ${ }^{19}$

After incubation, microbial growth was determined using two independent techniques: i) spectrophotometry and ii) fluorescent microscopy. For spectrophotometry, absorbance was determined at a wavelength of $600 \mathrm{~nm}$ for all sterilization treatments and controls. Additionally, transmitted light was used in conjunction with DAPI (4',6-diamidino-2-phenylindole) staining on the incubated media from each treatment and controls for observation of cells under a fluorescent microscope. This blue-fluorescent stain (excitation maximum at 358 $\mathrm{nm}$ and emission maximum at $461 \mathrm{~nm}$ ), widely used in fluorescence microscopy, stains DNA specifically. ${ }^{26}$ More details about these two methodologies can be found elsewhere. ${ }^{27}$

For a second, independent confirmation of the sterilization efficacy, an indirect, reverse sterilization approach was used. Deliberately contaminated clean, as-polished coupons were sterilized according to the same methods described above. Before sterilization, coupons were immersed in an Escherichia coli ATCC25404 culture grown overnight aerobically in LB broth. After sterilization, coupons were incubated and tested for bacterial growth following the direct method procedure. For this approach, controls included flasks containing (i) sterilized medium and no coupons (control 3), and (ii) sterilized medium and deliberately contaminated coupons (control 4).

Electrochemical methods.-Solutions for electrochemical testing.-The synthetic medium used for testing the corrosion response of the metal after sterilization procedures had a chemical composition similar to solutions used for growth of common fouling bacteria, ${ }^{28}$ with the exception that no $\mathrm{C}$ sources were included. YE was not added to the electrolytes used in electrochemical tests given that YE has been shown to affect corrosion measurements. ${ }^{29}$ The composition of the solution was (per liter): $3.0 \mathrm{~g}$ of $\mathrm{NaNO}_{3}, 0.7 \mathrm{~g}$ of $\mathrm{KH}_{2} \mathrm{PO}_{4}, 0.3 \mathrm{~g}$ of $\mathrm{MgSO}_{4} .7 \mathrm{H}_{2} 0,0.01 \mathrm{~g}$ of $\mathrm{CaCl}_{2} .2 \mathrm{H}_{2} \mathrm{O}, 0.02 \mathrm{~g}$ of $\mathrm{FeSO}_{4} .7 \mathrm{H}_{2} \mathrm{O}, 0.5 \mathrm{~g}$ of $\mathrm{NaCl}, 0.01 \mathrm{~g}$ of $\mathrm{MnCl}_{2} .4 \mathrm{H}_{2} \mathrm{O}$, and $2 \mathrm{~mL}$ of trace element solution. The composition of the trace element solution was (per liter): $0.75 \mathrm{~g}$ of $\mathrm{MnSO}_{4} \cdot \mathrm{H}_{2} \mathrm{O}, 0.75 \mathrm{~g}$ of $\mathrm{ZnSO}_{4} \cdot 7 \mathrm{H}_{2} 0$, $0.15 \mathrm{H}_{3} \mathrm{BO}_{3}, 0.08 \mathrm{~g}$ of $\mathrm{FeCl}_{3} \cdot 6 \mathrm{H}_{2} \mathrm{O}, 0.08 \mathrm{~g}$ of $\mathrm{CoCl}_{2} \cdot 6 \mathrm{H}_{2} \mathrm{O}, 0.075$ $\mathrm{CuSO}_{4} .5 \mathrm{H}_{2} \mathrm{O}$, and $0.05 \mathrm{~g} \mathrm{Na}_{2} \mathrm{MoO}_{4} .2 \mathrm{H}_{2} \mathrm{O}$. The $\mathrm{pH}$ of the solution remained between $4.50-4.70$ during testing. 
A separate set of samples was tested in $0.1 \mathrm{M} \mathrm{NaCl} \mathrm{pH} 4.50$ to compare the corrosivity of the synthetic medium to that of an electrolyte commonly used in corrosion investigations.

Electrochemical tests.-Electrochemical measurements were conducted using a conventional 3-electrode array. A platinum mesh was used as counter electrode, and a saturated calomel electrode (SCE) was used as a reference electrode. The reference electrode was connected to the solution through a Luggin capillary that was $1 \mathrm{~mm}$ in diameter and which was positioned between $2-3 \mathrm{~mm}$ from the sample. All tests were performed using a conventional potentiostat. A minimum of four samples was used per sterilization method, and four extra coupons were used as non-sterilized controls (control 5). An indirect assessment of the changes in surface condition caused by each sterilization treatment was obtained by comparing the corrosion response between sterilized and non-sterilized samples.

Electrochemical tests included:

Potentiodynamic polarization tests - Tafel slopes.-Potentiodynamic polarization tests were performed to determine Tafel slope values, necessary for corrosion rate (C.R.) calculations. ${ }^{30-34}$ Tests were performed after reaching a stable, i.e. $\pm 10 \mathrm{mV}$, open circuit potential $\left(\mathrm{E}_{\mathrm{OC}}\right)$, which usually occurred after 1 hour of exposure, at a scan rate of $0.167 \mathrm{mV} / \mathrm{s}$. The potential was scanned from $-200 \mathrm{mV}$ to $+200 \mathrm{mV}$ vs. $\mathrm{E}_{\mathrm{OC}}$.

Potentiodynamic polarization resistance measurements.-Potentiodynamic polarization resistance measurements were performed according to the $\operatorname{ASTM}^{\mathrm{f}}$ G59 specification with the following modifications. ${ }^{35}$ Tests were conducted after free corrosion potential stabilization, which typically took 60 minutes. Potentiodynamic polarization resistance measurements were taken at a scan rate of 0.167 $\mathrm{mV} / \mathrm{s} .{ }^{36}$ In this regard, the scan rate of $0.167 \mathrm{mV} / \mathrm{s}$ recommended by the standard was sufficiently slow to minimize hysteresis, ${ }^{37,38}$ and well below the maximum scan rate suggested by Mansfeld and Kendig and Townley. ${ }^{36,39}$ The potential range was $+/-25 \mathrm{mV}$ vs. $\mathrm{E}_{\mathrm{OC}}$. Polarization resistance $\left(R_{P}\right)$ values were obtained as the slope of the potential versus current density plot at $i=0 .{ }^{35,39,40} \mathrm{R}_{\mathrm{P}}$ values were then used to calculate corrosion rates via the Stern-Geary equation. ${ }^{35,40}$ Tafel slopes were used as inputs for this calculation; more details about these calculations are presented in the Results section. ${ }^{39-41}$

Non-electrochemical techniques.-Electrical Resistance (ER) probes.-An ER instrument was used to estimate the corrosion rate of carbon steel in ethanol and glutaraldehyde solutions. The studies were conducted using a UNS G10100 (AISI 1010) carbon steel probe with a wire-loop geometry. Probes were exposed for 20 days. The anticipated response time, i.e. the minimum time in which a reliable, measurable change takes place, of the probe was between 2 and 6 days, depending on the anticipated corrosion rate. ${ }^{42,43}$ Changes in electrical resistance were converted to corrosion rate values using the recommendations of the manufacturer.

Measurement of mass changes during isothermal heat treatments.-Isothermal heat treatments were performed to determine the oxidation kinetics of the material. Rectangular UNS G10100 (AISI 1010) carbon steel specimens with an approximate area of $8 \mathrm{~cm}^{2}$ were used. Five different temperatures were evaluated: 180, 300, 400, 500 and $600^{\circ} \mathrm{C}$. All tests were conducted in duplicate. Specimens were introduced into a furnace at room temperature. The furnace was then heated to the desired temperature, and it was maintained for 2 hours. The furnace was subsequently turned off, and the specimens were allowed to cool down in the furnace. Samples were weighed in an analytic balance to the nearest $0.1 \mathrm{mg}$ to determine weight loss or gain due to the different heat treatments.

\section{Table IV. Summary of control tests.}

Control $1 \quad$ Sterilized medium, no coupons; direct sterilization approach.

Control 2 Non-sterilized coupons; direct sterilization approach.

Control 3 Sterilized medium, no coupons; reverse sterilization approach.

Control 4 Contaminated coupons, no further sterilization; reverse sterilization approach.

Control 5 As polished coupons used in electrochemical tests; no sterilization applied. Synthetic medium.

Reproducibility and statistical analysis.-Tests to evaluate the efficacy of the various sterilization methods were conducted in triplicates (direct approach) and duplicates (indirect approach).

All electrochemical measurements were repeated at least in quadruplicates. An additional test was carried out when a large dispersion in corrosion rate values was observed (e.g. ethanol).

Given that potentiodynamic polarization resistance measurements can either under- or over-estimate polarization resistance depending on the direction of the polarization, ${ }^{44-46}$ each potentiodynamic polarization resistance measurement was repeated 6 times per sample, 3 in the forward direction and 3 in the backward direction, verifying minimum hysteresis between scans. For each sample, reported $R_{P}$ values are an average of these 6 measurements. Heat treatments to determine oxidation kinetics of plain carbon steel were performed in duplicate.

The range was used to estimate the variability in the results given that the number of replicate independent values, $n$, was small, i.e. $n<12$. The range, $w$, is defined as the difference between the maximum and minimum values in a set of replicate data values. ${ }^{47}$ As explained in ASTM G16, $w$ makes no assumption about the distribution of error given its non-parametric nature. Because in all instances $n<12$ and assuming a standard distribution, the standard deviation, S, was approximated as: ${ }^{47}$

$$
S=\frac{w}{\sqrt{n}} ; n<12
$$

\section{Results}

Table IV summarizes all control cases described throughout this study. Controls 1-4 are the control conditions used to evaluate the efficacy of the different sterilization procedures. Control 5 represents control conditions for all electrochemical tests.

Results of the direct sterilization procedure are shown in Figure 1. Figure 1a shows mean absorbance values measured at 600 $\mathrm{nm}$ for samples sterilized following the direct sterilization approach, whereas Figure $1 \mathrm{~b}$ shows those values for the reverse sterilization method. In both cases, samples were grouped by sterilization method.

Figure 2 compares potentiodynamic polarization resistance diagrams taken in the forward direction for the main sterilization procedures against the control (control 5). The average polarization resistance of six consecutive measurements, three in the forward direction and three in the reverse direction, is also included in each figure for comparison.

Polarization resistance values in $\Omega . \mathrm{cm}^{2}$ were obtained using conventional corrosion analysis software, as:

$$
R_{P}=\left(\frac{\partial \varepsilon}{\partial i}\right)_{\mathrm{E}=\mathrm{E}_{\mathrm{OC}}}
$$

where $\varepsilon$ is $\mathrm{E}_{-\mathrm{E}_{\mathrm{OC}}}$ in volts ${ }^{46,48,49}$.

Figure 3 compares anodic and cathodic polarization curves for the main sterilization procedures against control 5. For each replicate, Tafel slopes were estimated using conventional corrosion analysis software. Anodic Tafel slopes were determined at least $50 \mathrm{mV}$ away 


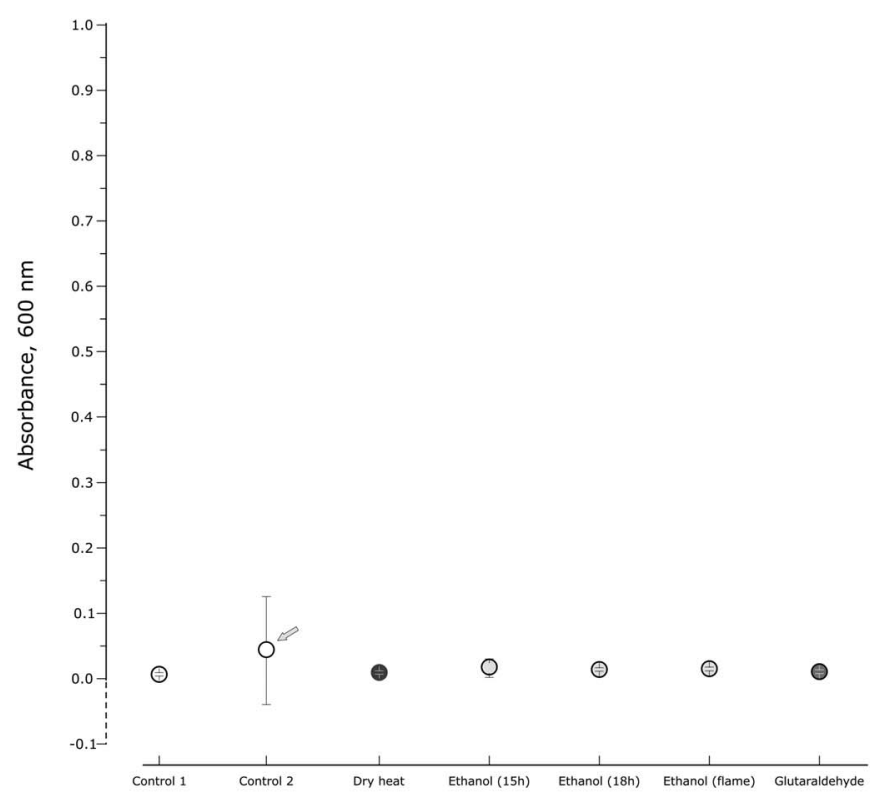

(a)

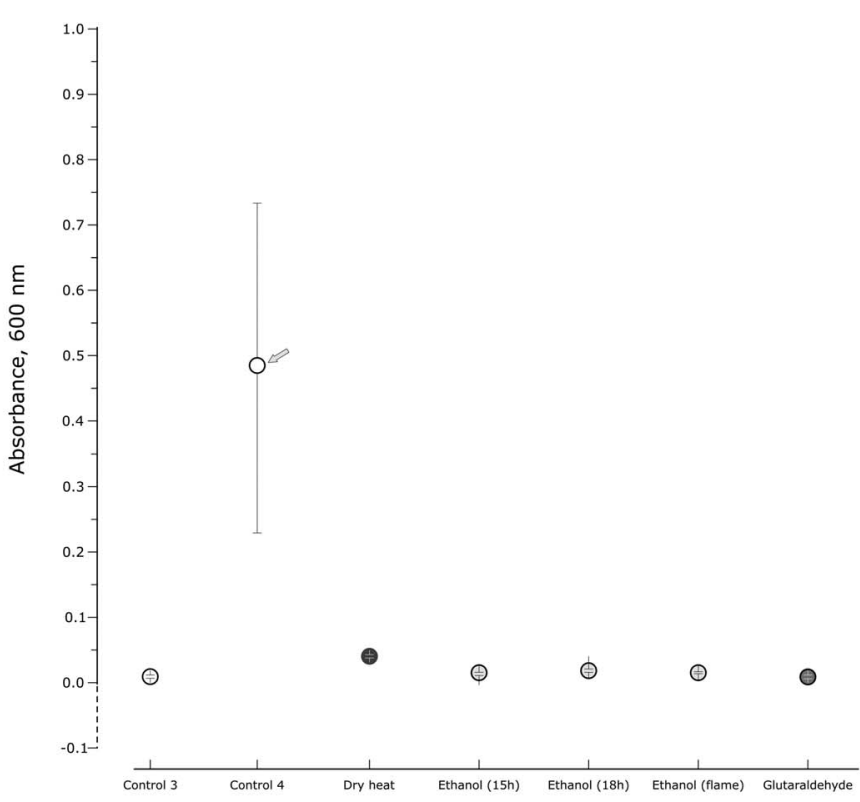

(b)

Figure 1. Mean absorbance values measured at $600 \mathrm{~nm}$ for samples used in (a) direct and (b) reverse sterilization efficacy confirmation. Error bars correspond to standard deviation values. The deviation is smaller than the symbols for points that do not have error bars. Arrow points to treatment where bacterial growth was observed after incubation. Results grouped by sterilization method.

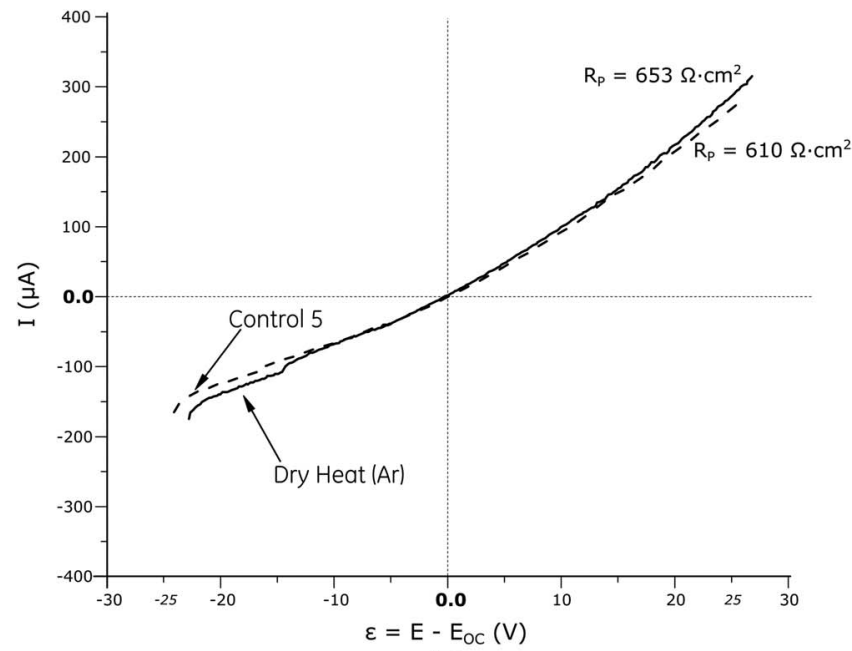

(a)

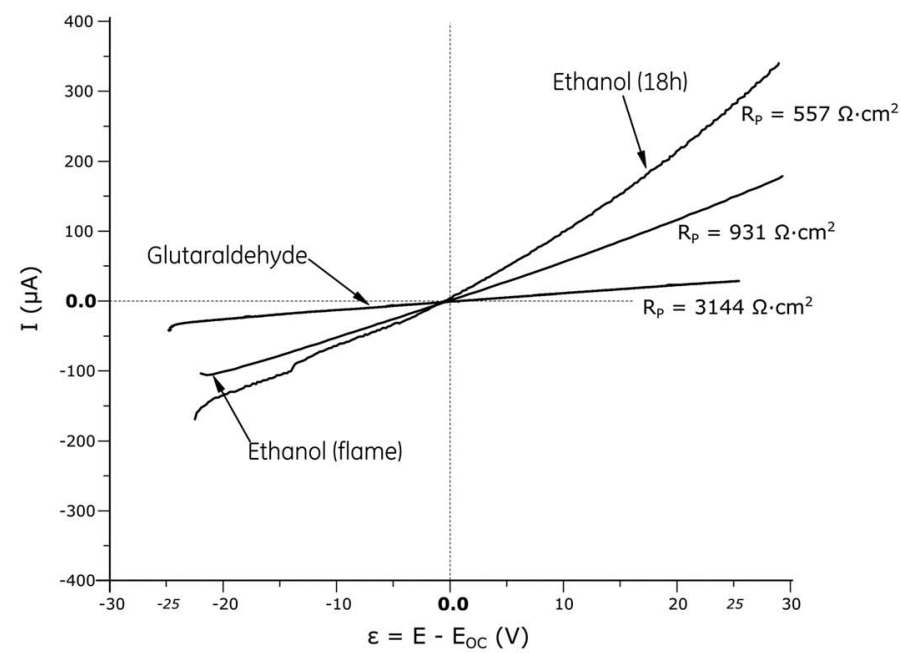

(b)

Figure 2. Typical UNS G10180 potentiodynamic polarization resistance curves for the main sterilization procedures, taken in the forward direction: (a) control 5 -dashed line- and dry heat (Ar) and (b) ethanol (18h) ethanol (flame), and glutaraldehyde. $R_{\mathrm{P}}$ values shown in the figures represent the average of six consecutive scans, three in the forward direction and three in the backward direction. All tests conducted in synthetic medium.

from $\mathrm{E}_{\mathrm{OC}}$, which gave a maximum error ${ }^{2}$ of approximately $7 \% .^{50}$ Anodic Tafel slope values were in line with values reporter by Stern and Weisert. ${ }^{51}$ Since cathodic curves were under mass-transfer control in all cases, Figure 3, cathodic Tafel slopes were approximated as $\beta_{\mathrm{c}} \rightarrow \infty$. Given that the Stern-Geary coefficient, B:

$$
B=\frac{\beta_{a} \cdot \beta_{c}}{2.303 \cdot\left(\beta_{a}+\beta_{c}\right)}
$$

is dominated by the smaller of the two Tafel slopes, $\mathrm{B}$ reduces to $\mathrm{B}=$ $\beta_{\mathrm{a}} / 2.303$ under cathodic mass transfer control. ${ }^{40,52}$
The corrosion current density, $\mathrm{i}_{\text {Corr }}$, in $\mu \mathrm{A} / \mathrm{cm}^{2}$ was subsequently determined as:

$$
i_{\text {corr }}=\frac{B}{R_{P}}
$$

and converted to corrosion rates in $\mathrm{mm} / \mathrm{y}$ using: ${ }^{53}$

$$
C R=3.27 \cdot 10^{-3} \frac{i_{\text {Corr }} \cdot E W}{\rho}
$$

where EW is the equivalent weight of the corroding species in grams per equivalent and $\rho$ is the density of the alloy in $\mathrm{g} / \mathrm{cm}^{3}$. EW and $\rho$ were approximated as $27.97 \mathrm{~g} / \mathrm{eq}$ and $7.87 \mathrm{~g} / \mathrm{cm}^{3}$, respectively. ${ }^{54}$

The solution resistance, $\mathrm{R}_{\mathrm{S}}$, was measured on a separate set of specimens exposed to either synthetic growth medium or $0.1 \mathrm{M} \mathrm{NaCl}$ 


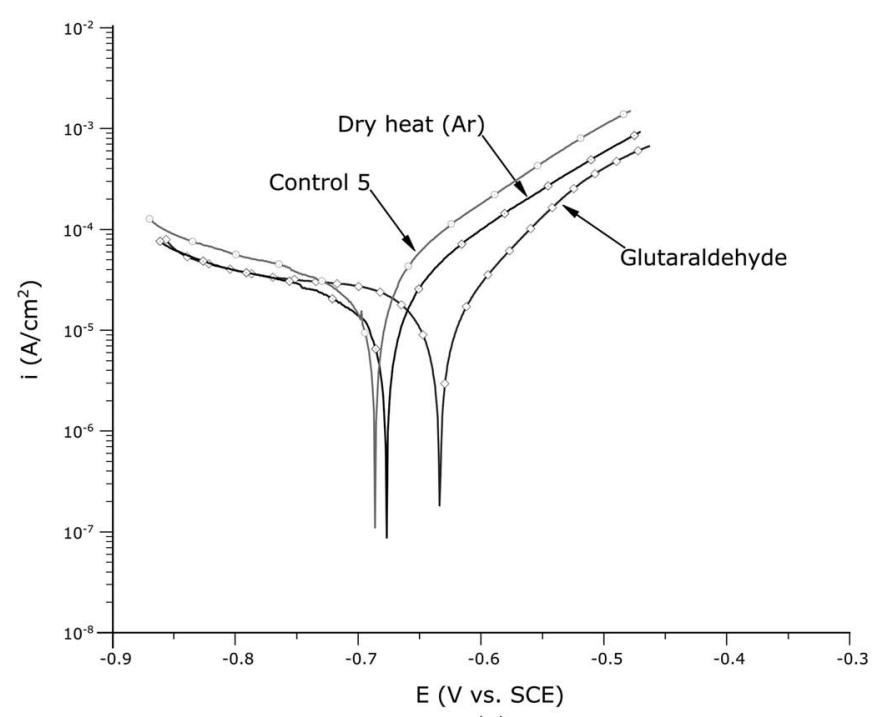

(a)

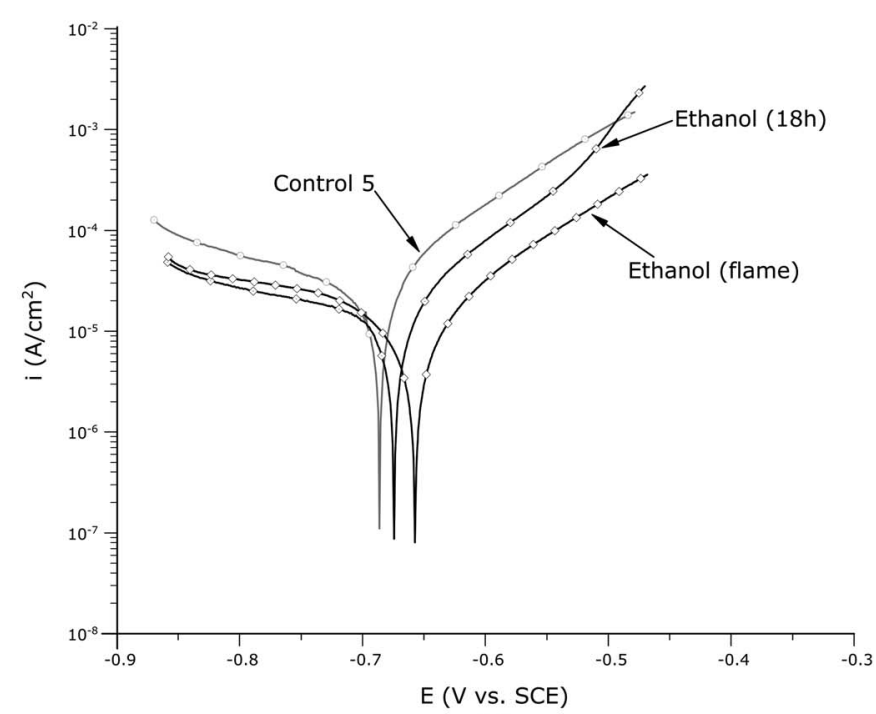

(b)

Figure 3. Typical UNS G10180 anodic and cathodic potentiodynamic polarization plots for the main sterilization procedures: (a) control 5, dry heat (Ar) and glutaraldehyde and (b) control 5, ethanol (18h), and ethanol (flame). All tests conducted in synthetic medium.

$\mathrm{pH}=4.50$ using Electrochemical Impedance Spectroscopy (EIS). EIS results showed that the average $\mathrm{R}_{\mathrm{S}}$ was $8.4 \pm 1.8 \Omega$. In the most conservative case, i.e. highest $R_{S}$ and the lowest $R_{P}, R_{S}$ was less than $3 \%$ of the total resistivity $\left(\mathrm{R}_{\mathrm{T}}\right)$, with an average of less than $1.5 \%$. Thus, the $\mathrm{R}_{\mathrm{S}}$ contribution to $\mathrm{i}_{\text {corr }}$ was not taken into account, i.e. $\mathrm{R}_{\mathrm{P}}>>\mathrm{R}_{\mathrm{S}}$.

Corrosion rates for all replicates of each sterilization method as estimated by potentiodynamic polarization resistance are shown in Figure 4. Mean corrosion rates, steady state $\mathrm{E}_{\mathrm{OC}}, \mathrm{E}_{\mathrm{OC}}$ standard deviation, anodic and cathodic Tafel slopes, as well as minimum and maximum values, the range and the standard deviation are shown in Table V. Corrosion rates of UNS G10180 (AISI 1018) samples in 0.1 $\mathrm{NaCl}$ at $\mathrm{pH} 4.50$ and reference values for the corrosion rate of carbon steel in aerated fresh ${ }^{55,56}$ and seawater ${ }^{57,58}$ are also included for comparison. In all cases, results were grouped based on sterilization method.
The corrosion rate of UNS G10100 (AISI 1010) in $75 \mathrm{vol} \%$ ethanol and 2 vol\% glutaraldehyde as measured by a wire-loop ER probe is shown in Figure 5. In Figure 5, a vertical dashed line indicates the response time of the probe. Since the response time of an ER probe depends on the anticipated corrosion rate, ${ }^{43}$ a conservative response time was calculated by assuming an average corrosion rate of 0.05 $\mathrm{mm} / \mathrm{y}$. Data points taken below the probe's response time are indicated by dashed symbols. Finally, Figure 6 summarizes weight change as a function of temperature.

\section{Discussion}

Sterilization efficacy.-All sterilization methods deactivated microorganisms on the metal surface. Solutions from direct sterilization treatments showed no difference in optical density (OD) when compared to the sterilized medium containing no coupons (control 1,

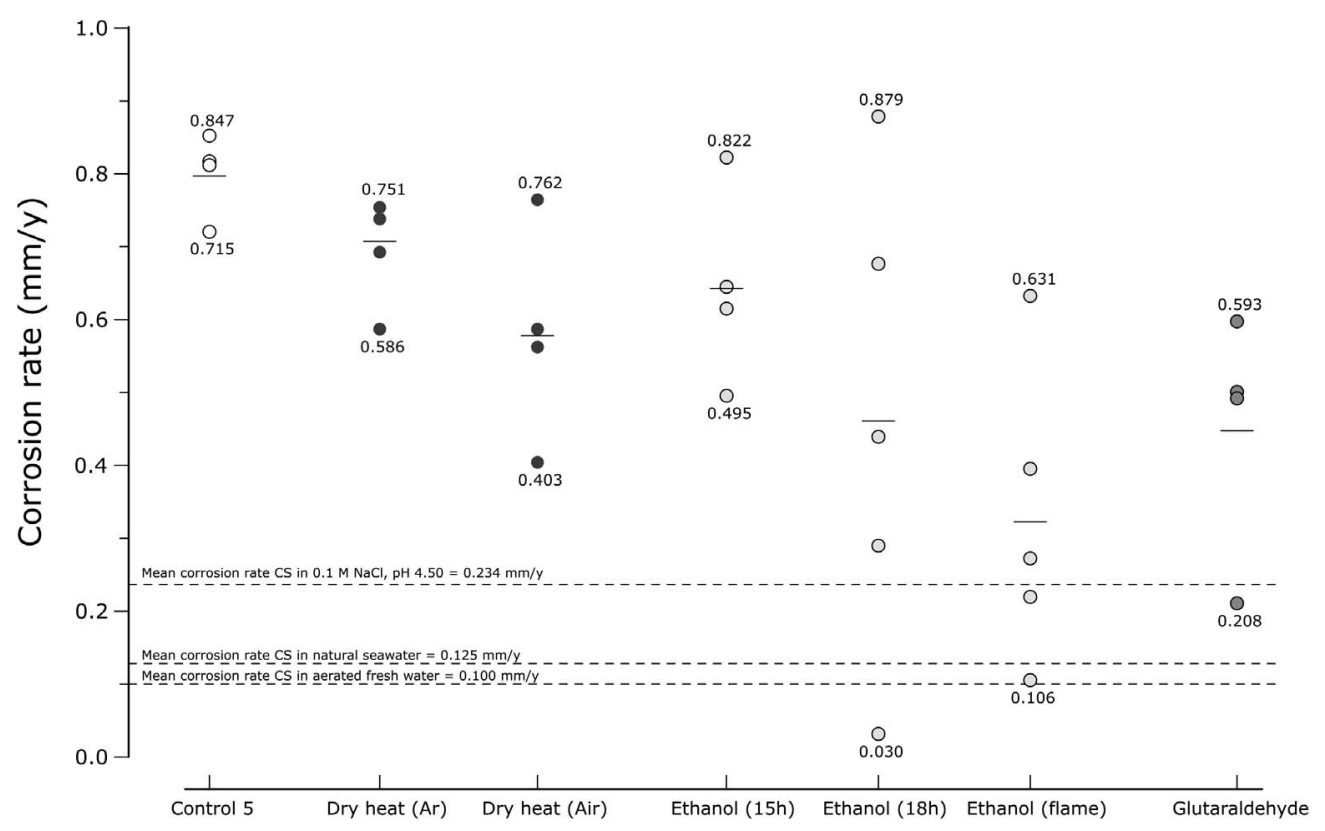

Figure 4. Corrosion rate values as determined by the potentiodynamic polarization resistance method. Results grouped by sterilization method. Corrosion rates in fresh water ${ }^{5,56}$ and seawater ${ }^{57,58}$ are added as a reference. The short horizontal lines indicate the mean corrosion rate. 
Table V. Corrosion rate measurements obtained by the potentiodynamic polarization resistance method.

\begin{tabular}{|c|c|c|c|c|c|c|c|c|c|}
\hline Treatment & $\begin{array}{c}\text { AVG OCP } \\
\left(\mathrm{V}_{\mathrm{SCE}}, \mathrm{SCE}\right)\end{array}$ & $\begin{array}{l}\text { STD E EC } \\
\left(\mathrm{mV}_{\mathrm{SCE}}\right)\end{array}$ & $\begin{array}{l}\text { AVG Anodic } \\
\text { Tafel Slope, } \beta_{\mathrm{a}} \\
\text { (V/decade) }\end{array}$ & $\begin{array}{c}\text { AVG Cathodic } \\
\text { Tafel Slope, } \beta_{\mathrm{c}} \\
\text { (V/decade) }\end{array}$ & $\begin{array}{c}\text { Mean C.R. } \\
(\mathrm{mm} / \mathrm{y})\end{array}$ & $\begin{array}{l}\text { Max. C.R. } \\
(\mathrm{mm} / \mathrm{y})\end{array}$ & $\begin{array}{l}\text { Min. C.R. } \\
(\mathrm{mm} / \mathrm{y})\end{array}$ & $\begin{array}{l}\text { C.R. Range, } \\
w(\mathrm{~mm} / \mathrm{y})\end{array}$ & $\begin{array}{l}\text { C.R. STD, } \\
\text { S (mm/y) }\end{array}$ \\
\hline Control 5 & -0.693 & 8.1 & 0.093 & $\infty$ & 0.797 & 0.847 & 0.715 & 0.132 & 0.0660 \\
\hline Dry heat (air) & -0.674 & 7.4 & 0.083 & $\infty$ & 0.578 & 0.762 & 0.403 & 0.360 & 0.1800 \\
\hline 75 vol\% Ethanol, 15 hours & -0.687 & 10.7 & 0.107 & $\infty$ & 0.644 & 0.822 & 0.495 & 0.327 & 0.1635 \\
\hline 75 vol\% Ethanol, 18 hours & -0.677 & 70.64 & 0.111 & $\infty$ & 0.461 & 0.879 & 0.030 & 0.849 & 0.379 \\
\hline $0.1 \mathrm{M} \mathrm{NaCl} \mathrm{pH} 4.50$ & -0.548 & 13.6 & 0.057 & $\infty$ & 0.234 & 0.284 & 0.136 & 0.148 & 0.074 \\
\hline
\end{tabular}

Figure 1a). Furthermore, microorganisms were not detected by microscopy. Only solutions from non-sterilized controls (control 2, Figure 1a) showed increased optical density; the presence of microorganisms was later confirmed visually under the microscope.

Reverse sterilization tests, in which microorganisms where intentionally grown on the surface, provided further evidence of the efficacy of the different treatments used in this study. No difference in growth medium optical density was observed in almost all sterilization methods when compared to flasks containing sterilized medium exclusively (control 3, Figure 1b). The absence of microorganisms was later confirmed under the optical microscope. The only treatment that showed a slight increase in optical density was dry heat. No microorganisms were detected by microscopy, but rather the presence of debris from the oven-dried biofilm that had formed during the deliberate contamination that led to a slightly higher OD in LB medium.

As expected, contaminated controls (control 4, Figure 1b) had increased optical density, associated with microbial contamination, which was later confirmed by optical microscopy.

Because in the direct sterilization approach specimens were immersed in a rich growth medium, it is plausible that microorganisms that cannot be cultured in this commonly used broth might have survived the sterilization process. In that case, the direct approach would not have detected the presence of such microorganisms. However, the efficacy of the sterilization methods was also assessed following a reverse procedure, determining their effectiveness in killing living bacterium (i.e. E. coli ATCC25404.) The results presented herein suggested that all sterilization methods eliminated living bacteria from the metal surface when intentionally contaminated. Furthermore, contamination did, in fact, occur in the untreated control case but did not in the sterilized samples, implying that all sterilization methods were capable of eliminating not only living microorganisms but also, at a minimum, all those that can be cultured in the LB broth. The use of different growth media and complimentary detection techniques such as culture independent approaches to detecting activity could give additional information about sterilization efficacy, which was outside the scope of this work.

Electrochemical tests._-Understanding the effects of sterilization treatments on the corrosion behavior of the alloy is critical to MIC research. The ideal sterilization treatment will effectively kill all living microorganisms and spores on the surface without altering the surface condition of the sample, assessed here by the electrochemical response of the material. Corrosion rates, therefore, have to be similar on average, with a dispersion (estimated using the range) within the variability of the untreated control. In this regard, a large corrosion rate

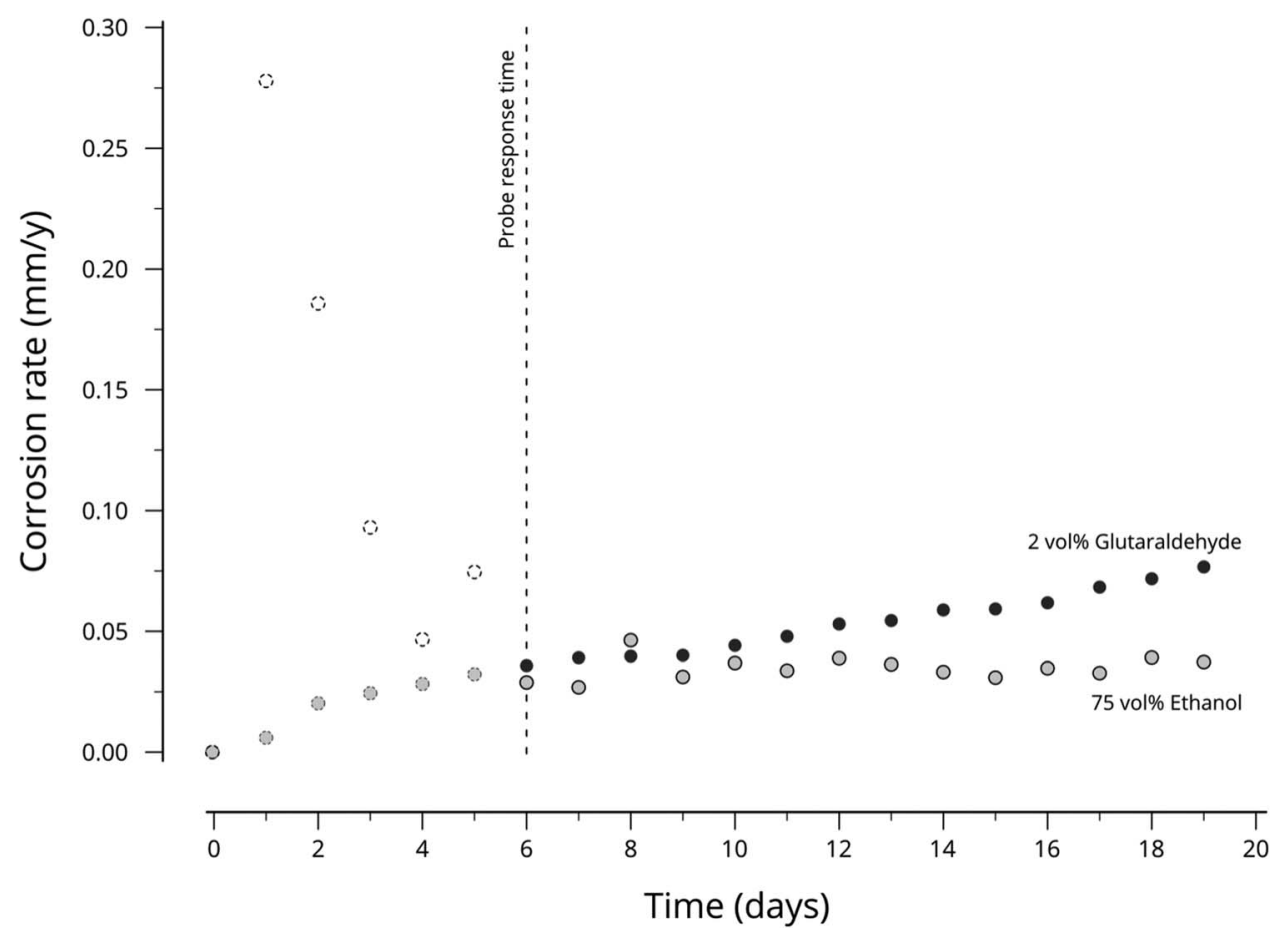

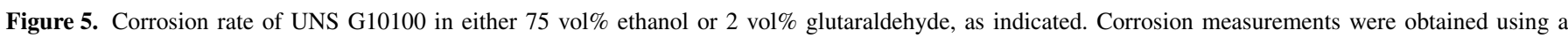
commercial wire-loop ER probe. 


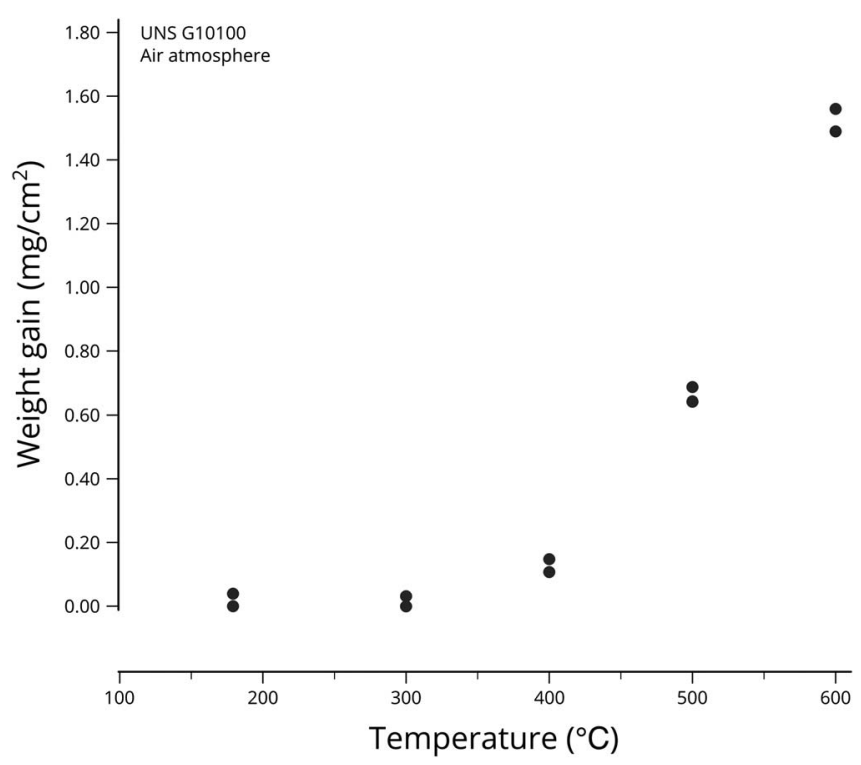

Figure 6. Weight gain of UNS G10100 exposed to oven air as a function of temperature.

spread adds a source of error and could lead to the misinterpretation of the data.

All sterilization procedures had some net effect on the electrochemical response of the material (Figure 4). The effect of the sterilization procedure was more pronounced on corrosion rates than on $\mathrm{E}_{\mathrm{OC}}$, Table V. Nevertheless, the $\mathrm{E}_{\mathrm{OC}}$ in ethanol (18h) and ethanol followed by flaming gave the largest spread. Exposure to $75 \%$ ethanol for $18 \mathrm{~h}$ and ethanol followed by flaming led to standard deviations that were, respectively, 8.7 and 7.0 times higher than that of control 5.

Corrosion rates of coupons treated with dry heat under an inert argon atmosphere had an average corrosion rate as well as a range and standard deviation similar to the $w$ and $S$ values of the control (i.e. $\mathrm{w}=0.165$ versus $0.132 \mathrm{~mm} / \mathrm{y}$ and $\mathrm{S}=0.0825 \mathrm{vs} .0 .0660$, respectively or $25 \%$ higher than the control), control 5 . Coupons treated using dry heat in air, in contrast, showed a slight decrease in average corrosion rate; however, the $0.360 \mathrm{~mm} / \mathrm{y}$ range and the $0.18 \mathrm{~mm} / \mathrm{y}$ standard deviation were 2.7 times higher than that of control 5 .

Sterilization in $75 \mathrm{vol} \%$ ethanol had a marked effect on corrosion, which was a function of sterilization time. The average corrosion rate after 15 hours was lower than the control (control 5) with a range and a standard deviation similar to that of dry heat in air. Sterilizing the coupons 18 hours in ethanol, however, resulted in the highest data variability, with a difference between maximum and minimum corrosion rates of almost an order of magnitude. Sterilization by flaming gave the largest decrease in mean corrosion rates with a $w$ value of $0.524 \mathrm{~mm} / \mathrm{y}$ and $\mathrm{S}$ of $0.262 \mathrm{~mm} / \mathrm{y}$, or 4 times higher than the control (control 5). Finally, samples sterilized in 2 vol\% glutaraldehyde showed a mean corrosion rate similar to that of an $18 \mathrm{~h}$ sterilization in $75 \mathrm{vol} \%$ ethanol and a considerable variability with $\mathrm{w}=0.385 \mathrm{~mm} / \mathrm{y}$ and $\mathrm{S}=0.1925 \mathrm{~mm} / \mathrm{y}$.

The large spread caused by sterilization in 75 vol\% ethanol and 2 vol\% glutaraldehyde can, in part, be explained by the corrosivity of the medium toward carbon steel. In most cases, exposure to $75 \mathrm{vol} \%$ ethanol and 2 vol\% glutaraldehyde produced visible rust spots and discoloration of the electrolyte after 15 hours. Corrosion rate estimations using ER probes in $75 \mathrm{vol} \%$ ethanol and $2 \mathrm{vol} \%$ glutaraldehyde were conducted to try to explain these observations.

Although the conservative probe response time calculated herein was longer than the actual sterilization period, corrosion rates were used as an indicator of the corrosivity of the environment. In this regard, corrosion rates as estimated by ER probe measurements, taken after the initial probe stabilization period (Figure 5), were in the 0.025 to $0.075 \mathrm{~mm} / \mathrm{y}$ (0.985 to $2.955 \mathrm{mpy})$ range. Those non-negligible corrosion rates represent $20 \%$ and $60 \%$ of the accepted corrosion rate of carbon steel in aerated, quiet (i.e. moving at less than $0.6 \mathrm{~m} / \mathrm{s}$ ) seawater $^{57,58}$.

Influence of the electrolyte composition.-In addition to the effect of the sterilization treatment, the influence of the electrolyte used for corrosion testing has to be considered. MIC research is typically conducted using complex electrolytes that add a significant number of components necessary to promote microbial growth. As discussed by Webster and Newman, ${ }^{59}$ the corrosivity of these nutrient-rich synthetic media can be quite different from that of the actual service environment, e.g. fresh- and seawater.

Figure 4 shows that the corrosion rate of carbon steel (control 5) in the complex solution used herein was, on average, 3.4 times faster than that in a $0.1 \mathrm{M} \mathrm{NaCl}$ solution tested at the same $\mathrm{pH}$ value of 4.50 . Although short-term laboratory experiments in simulated environments cannot be used to predict long-term corrosion rates in natural environments, it is illustrative to compare the short-term behavior of carbon steel in the synthetic electrolyte employed in this investigation with the long-term behavior in fresh- and sea-water. ${ }^{37,60}$ Corrosion rates in the sterile synthetic medium were 8 times faster than reported mean corrosion rates of carbon steel in fresh waters ${ }^{55,56}$ and 6.35 times faster than reported values for carbon steel in natural seawater. ${ }^{57,58}$ Comparing corrosion rates from a MIC investigation against typical corrosion rates in service could be misleading. A negative control, i.e. a control without microorganisms, in the actual sterile synthetic medium is necessary to separate the effect of microorganisms from that of the inorganic and organic species added to the electrolyte. In this regard, some compounds can either enhance corrosion (e.g. $\mathrm{Fe}^{3+}$ and $\mathrm{NO}_{3}{ }^{-}$) by acting as added oxidizing agents or slow/inhibit dissolution kinetics by the formation of surface protective films (e.g. phosphates) ${ }^{61,62}$ YE additions have also been shown to affect corrosion results. ${ }^{29}$

Oxidation kinetics. - The evidence presented above suggested that dry heat was the most convenient sterilization procedure for carbon steel. However, prolonged heating at moderately elevated temperatures could potentially alter the surface properties and microstructure of the steel. Additional tests were performed to determine the maximum allowable temperature for dry heat sterilization.

As seen in Figure 6, even when exposed to air, oxide formation was minimal during dry heat sterilization given the relatively low temperatures of the procedure. Likewise, Figure 6 shows that weight gain due to oxidation was measurable with an analytical balance only at temperatures above $400^{\circ} \mathrm{C}$. Weight gain during carbon steel and iron oxidation is sensitive to the amount of cold work and sample preparation methods like electropolishing or mechanical grinding. ${ }^{63}$ Despite this, weight gain of samples exposed to temperatures above $400^{\circ} \mathrm{C}$ was in reasonable agreement with the value expected using parabolic growth law with coefficients reported in the literature. ${ }^{64-66}$ For samples exposed to $400^{\circ} \mathrm{C}$ or above, the corrosion rate in the test solution exhibited a drastic decrease (not shown), probably due to the formation of protective oxides. Oxide growth should not be an a priori matter of concern for sterilization of carbon steel when conducted at $150-180^{\circ} \mathrm{C}$.

Use of dry heat sterilization on other alloys.-Based on the results presented herein, it may be tempting to assume that dry heat sterilization in inert atmospheres could be used on other alloys. Even though no microstructural changes on carbon steel due to sterilization treatments at 150 to $180^{\circ} \mathrm{C}$ are expected based on the kinetics of the $\mathrm{Fe}-\mathrm{C}-\mathrm{Mn}$ system, it is well known that prolonged heating at moderately elevated temperature can produce grain growth and aging of precipitation hardenable alloys, such as wrought aluminum alloys. ${ }^{67}$ While dry heat sterilization in an inert atmosphere should work equally well on carbon and low alloy steels as on most stainless steels and nickel-based alloys, heating in the $150-180^{\circ} \mathrm{C}$ range could result in precipitation hardening of, e.g., most wrought aluminum alloys used in aerospace applications. ${ }^{67}$ The effect of possible microstructural 
changes due to the sterilization procedure must be taken into account in MIC research.

\section{Conclusions}

Based on the evidence presented herein the following conclusions were drawn:

- All sterilization methods were equally effective in eliminating microorganisms and spores from the metal surface as determined directly, by culture in LB broth, and indirectly by determining the efficacy in killing living microorganisms in intentionally contaminated surfaces.

- All sterilization methods introduced a source of error as determined by linear polarization measurements. This publication presents a methodology that could be followed by other laboratories to evaluate the effect of alternative sterilization treatments in specific laboratory settings.

- Dry heating at $170^{\circ} \mathrm{C}$ for 60 minutes (plus heating and cooling times) in an inert atmosphere was the most convenient sterilization method for carbon steels regarding practicality and consistency in the response of the metal to its application.

- While dry heat sterilization in an inert atmosphere should be equally adequate for all carbon, low alloy, and most stainless steels as well as nickel-based alloys, prolonged heating at $150-180^{\circ} \mathrm{C}$ could lead to microstructural changes in some age-hardenable alloys.

- Sterilization of carbon steels in $75 \mathrm{vol} \%$ ethanol and 2 vol\% glutaraldehyde as well as alcohol followed by flaming is discouraged given the large dispersion in electrochemical response caused by the exposure to the sterilization media.

\section{Acknowledgments}

The authors thank Prof. Lu-Kwang Ju, Prof. Ricardo M. Carranza, Robert Miller II, Hua Wang, and Álvaro Rodríguez for their advice and technical assistance with the project.

This work is associated with the National Center for Education and Research on Corrosion and Materials Performance (NCERCAMP) at The University of Akron and the DoD Technical Corrosion Collaboration supported by the U.S. Department of Defense Corrosion Policy and Oversight through the Engineering Research and Development Center/US Army Construction Engineering Research Laboratory grant W9132T-11-0002, and through the US Air Force Academy under agreement number FA7000-10-2-0013.

\section{References}

1. B. Little, P. Wagner, and F. Mansfeld, Electrochim. Acta, 37, 2185 (1992).

2. H. A. Videla, Rev Metal Madrid, 256 (2003).

3. H. A. Videla and W. G. Characklis, International Biodeterioration \& Biodegradation, 29, 195 (1992).

4. H. A. Videla, Manual of Biocorrosion, CRC Lewis Publishers, Boca Raton, FL (1996).

5. ISO 11138 Parts 1-5 Sterilization of health care products-Biological indicators, International Organization for Standardization, Geneva, Switzerland (2006).

6. I. B. Beech and C. C. Gaylarde, in Proceedings of 2nd International EFC Workshop on Microbial Corrosion, p. 61, Sesimbra, Portugal (1991).

7. N. Sridhar, C. S. Brossia, D. S. Dunn, and A. Anderko, Corrosion, 60, 915 (2004).

8. U. Steinsmo, T. Rogne, and J. Drugli, Corrosion, 53, 955 (1997).

9. R. Gundersen, B. Johansen, P. O. Gartland, L. Fiksdal, I. Vintermyr, R. Tunold, and G. Hagen, Corrosion, 47, 800 (1991).

10. M. H. Dorsey, D. R. Demarco, B. J. Saldanha, G. A. Fisher, L. Yang, and N. Sridhar Paper No. 05371 "Laboratory Evaluation of a Multi-Array Sensor for Detection of Underdeposit Corrosion and/or Microbially Influenced Corrosion," CORROSION/05, (NACE International, Houston, TX, 3-7 April, 2005).

11. A. Lugauskas, I. Prosycevas, R. Ramanauskas, A. Griguceviciene, A. Selskiene, and V. Pakstas, Mater Sci-Medzg, 15, 224 (2009).

12. S. J. Yuan and S. O. Pehkonen, Colloids Surf B Biointerfaces, 59, 87 (2007).

13. R. Stadler, W. Fuerbeth, K. Harneit, M. Grooters, M. Woellbrink, and W. Sand, Electrochim. Acta, 54, 91 (2008).

14. K. Miyanaga, R. Terashi, H. Kawai, H. Unno, and Y. Tanji, Biotechnol. Bioeng., 97, 850 (2007).

15. D. Clover, B. Kinsella, B. Pejcic, and R. De Marco, J. Appl. Electrochem., 35, 139 (2005)
16. R. E. Melchers, Corros Sci, 46, 1669 (2004).

17. R. L. Bertolotti and V. Hurst, The Journal of the American Dental Association, 97, 628 (1978).

18. ISO 11138 Sterilization of health care products - Moist heat-Part 1: Requirements for the development, validation and routine control of a sterilization process for medical devices., International Organization for Standardization, Geneva, Switzerland (2006).

19. W. A. Rutala and D. J. Weber, Guideline for disinfection and sterilization in healthcare facilities, Centers for Disease Control (2008).

20. ISO 11138 Sterilization of health care products - Biological indicators - Part 4 Biological indicators for dry heat sterilization processes, International Organization for Standardization, Geneva, Switzerland (2006).

21. H. Castaneda and X. D. Benetton, Corros. Sci., 50, 1169 (2008).

22. C. A. González-Rodríguez, F. J. Rodríguez-Gómez, and J. Genescá-Llongueras, Electrochim. Acta, 54, 86 (2008).

23. J. D. Gu, D. B. Mitton, T. E. Ford, and R. Mitchell, Biodegradation, 9, 39 (1998).

24. S. Y. Li, Y. G. Kim, K. S. Jeon, Y. T. Kho, and T. Kang, Corrosion, 57, 815 (2001).

25. L.-K. Ju, in Personal communication to authors (2011).

26. K. G. Porter and Y. S. Feig, Limnol Oceanogr, 25, 943 (1980).

27. R. B. Miller, 2nd, A. Sadek, A. Rodriguez, M. Iannuzzi, C. Giai, J. M. Senko, and C. N. Monty, PLoS One, 11, e0147899 (2016).

28. A. Raya, M. Sodagari, N. M. Pinzon, X. He, B.-M. Zhang Newby, and L.-K. Ju, Environ Sci Pollut Res Int, 17, 1529 (2010).

29. J. Lee and B. Little, Corrosion, 71(12), 1434 (2015).

30. G. T. Burstein, Corros. Sci., 47, 2858 (2005).

31. G. Kear and F. Walsh, Corrosion and Materials, 30, S1 (2005).

32. M. Pourbaix, Corros. Sci., 14, 25 (1974).

33. J. Tafel, Z. Phys. Chem, 50, 641 (1905).

34. J. Tafel and K. Naumann, Z. Phys. Chem., 50, 713 (1905).

35. ASTM G59-97 Standard Test Method for Conducting Potentiodynamic Polarization Resistance Measurements, ASTM International, West Conshohocken, PA (2014).

36. D. W. Townley, Corrosion, 47, 737 (1991)

37. B. Syrett and D. Macdonald, Corrosion, 35, 505 (1979).

38. G. Rocchini, Corros. Sci., 38, 2095 (1996).

39. F. Mansfeld and M. Kendig, Corrosion, 37, 545 (1981).

40. J. Scully, Corrosion, 56, 199 (2000)

41. D. D. Macdonald and M. C. H. McKubre, in STP727-EB Electrochemical corrosion testing, F. Mansfeld and U. Bertocci Editors, p. 110, ASTM International, West Conshohoken, PA (1981).

42. ASTM G96-90 Standard Guide for Online Monitoring of Corrosion in Plant Equipment (Electrical and Electrochemical Methods), ASTM International, West Conshohocken, PA (2013).

43. A. J. Perkins, Paper No. 286 "A Review of the New ASTM G96-90 Standard Guide for On-Line Monitoring in Plant Equipment," CORROSION/92, (NACE International, Houston, TX, 1992).

44. F. Mansfeld, in Advances in Corrosion Science and Technology - Volume 6, M. G. Fontana and R. Staehle Editors, p. 163, Springer US, New York (1976)

45. F. Mansfeld, Paper No. 106 "Evaluation of polarization resistance round robin testing conducted by ASTM G01.11," CORROSION/76, (NACE International, Houston, TX 1976).

46. G. W. Walter, Corros. Sci., 17, 983 (1977)

47. ASTM G16-13 Standard Guide for Applying Statistics to Analysis of Corrosion Data ASTM International, West Conshohocken, PA (2013).

48. G. Rocchini, Corros. Sci., 33, 1593 (1992).

49. R. V. Skold and T. E. Larson, Corrosion, 13, 139t (1957).

50. D. A. Jones, Corrosion, 28, 180 (1972).

51. M. Stern and E. D. Weiser, in Proceedings Vol. 59 American Society for Testing and Materials, p. 1280, Philadelphia, PA (1959).

52. I. Epelboin, G. Gabrielli, M. Keddam, and H. Takenouti, in Electrochemical Corrosion Testing, STP28031S, F. Mansfeld and U. Bertocci Editors, p. 150, ASTM International, West Conshohoken, PA (1981).

53. ASTM G102-89 Standard Practice for Calculation of Corrosion Rates and Related Information from Electrochemical Measurements, ASTM International, West Conshohocken, PA (2015)

54. D. A. Jones, in Principles and Prevention of Corrosion, 2nd ed., p. 78, Prentice Hall, Upper Saddle River, NJ (1996).

55. S. C. Dexter, Handbook of oceanographic engineering materials, Wiley, New York (1979).

56. I. Matsushima, in, R. W. Revie Editor, p. 589, John Wiley \& Sons, Inc., New York, NY (2011).

57. M. G. Fontana, in Corrosion Engineering, p. 374, McGraw-Hill International Editions, Singapore (1986).

58. I. Matsushima, in Uhlig's Corrosion Handbook, 3rd ed., R. W. Revie Editor, p. 601, John Wiley \& Sons, Inc., New York, NY (2011).

59. B. J. Webster and R. C. Newman, in STP1232-EB: Microbiologically Influenced Corrosion Testing, J. Keams and B. J. Little Editors, p. 28, ASTM International, West Conshohoken, PA (1994).

60. E. McCafferty, Corros. Sci., 47, 3202 (2005).

61. M. J. Franklin, D. C. White, and H. S. Isaacs, Corros. Sci., 33, 251 (1992).

62. D. A. Jones and P. S. Amy, Industrial \& Engineering Chemistry Research, 39, 575 (2000).

63. R. Y. Chen and W. Y. D. Yuen, Oxid. Met., 59, 433 (2003)

64. N. Bertrand, C. Desgranges, D. Gauvain, D. Monceau, and D. Poquillon, Mater. Sci. Forum, 461-464, 591 (2004).

65. N. Bertrand, C. Desgranges, D. Poquillon, M. C. Lafont, and D. Monceau, Oxid. Met., 73, 139 (2010). 
66. J. J. Senkevich, D. A. Jones, and I. Chatterjee, Corros. Sci., 42, 201 (2000).

67. J. R. Davis, in ASM specialty handbook, Joseph R. Davis \& Associates Editor, p. 290 ASM International, Materials Park, OH (1993).

68. F. P. de França and M. T. S. Lutterbach, J. Ind. Microbiol., 17, 6 (1996).

69. R. B. Eckert, H. C. Aldrich, C. A. Edwards, and C. B. Yang, Paper No. 519 "Guidelines for Reproducing Microbiologically Influenced Corrosion Initiation on Carbon Steels under Controlled Conditions," CORROSION/06, (NACE International, San Diego, CA, 12-16 March, 2006).

70. R. G. J. Edyvean, A. D. Maines, C. J. Hutchinson, N. J. Silk, and L. V. Evans, International biodeterioration \& biodegradation, 29, 251 (1992).

71. C. G. Peng and J. K. Park, Corrosion, 50, 669 (1994).
72. V. B. Rodin, S. K. Jigletsova, V. S. Kobelev, N. A. Akimova, N. V. Aleksandrova, G. E. Rasulova, and V. P. Kholodenko, Appl Biochem Micro+, 36, 589 (2000).

73. R. A. Royer and R. F. Unz, Corrosion, 58, 863 (2002).

74. M. Stranger-Johannessen, in Biodeterioration 7: Selected papers presented at the 7 th International Biodeterioration Symposium, D. R. Houghton, R. N. Smith, and H. O. W. Eggins Editors, p. 372, Cambridge, UK (1988).

75. Y. Tanji, T. Itoh, T. Nakano, K. Hori, and H. Unno, Corrosion, 58, 232 (2002).

76. E. Valencia-Cantero, J. J. Pena-Cabriales, and E. Martinez-Romero, Geomicrobiol. J., 20, 157 (2003).

77. J. Wen, K. Zhao, T. Gu, and S. Nesic, Paper No. 666 "Effects of Mass Transfer and Flow Conditions on SRB Corrosion of Mild Steel," CORROSION/06, (NACE International, San Diego, CA, 12-16 March, 2006). 